\title{
PENENTUAN MODEL REGRESI TERBAIK DENGAN MENGGUNAKAN METODE STEPWISE (STUDI KASUS : IMPOR BERAS DI SULAWESI UTARA)
}

\author{
Selfina Clara Wohon ${ }^{1)}$, Djoni Hatidja ${ }^{1 *}$, Nelson Nainggolan ${ }^{1)}$ \\ ${ }^{1)}$ Program Studi Matematika, Fakultas Matematika dan Ilmu Pengetahuan Alam, \\ Universitas Sam Ratulangi Manado \\ *) Coresponding author: dhatidja@gmail.com \\ e-mail : sclarawohon@yahoo.co.id; dhatidja@gmail.com; n-nelson@unsrat.ac.id
}

\begin{abstract}
ABSTRAK
Indonesia memiliki lahan pertanian yang cukup besar dan tentulah mampu memenuhi kebutuhan beras masyarakatnya, tetapi pada kenyataan produksi beras di Indonesia belum dapat memenuhi permintaan masyarakat sehingga pemerintah mengambil kebijakkan untuk mengadakan impor beras agar kebutuhan terpenuhi. Penelitian ini bertujuan untuk mengetahui variabel-variabel yang mempengaruhi impor beras di Sulawesi Utara dan menentukan model regresi terbaiknnya. Penelitian dilakukan di Kota Manado, Sulawesi Utara dan berlangsung selama 5 bulan sejak November 2016 sampai April 2017. Data yang digunakan adalah data sekunder tahunan Badan Pusat Statistik yang diolah dari buku Sulawesi Utara dalam Angka 2008-2016. Data yang diperoleh dianalisi dengan Metode regresi Stepwise. Variabel-variabel yang mempengaruhi impor beras di Sulawesi Utara yaitu penerimaan beras dari dalam negeri $\left(\mathrm{X}_{4}\right)$ dan devisa impor unpaid pada bea dan cukai Bitung $\left(\mathrm{X}_{8}\right)$ yang membentuk model regresi terbaik $\hat{Y}=26322,228-$ $0,626 X_{4}+0.001 X_{8}$ dengan nilai $\mathrm{R}$-sqr $=93,7 \%$ dan $\mathrm{R}$-adj $=91,8 \%$. Variabel-variabel tersebut cukup baik untuk menduga besar jumlah impor beras di Sulawesi Utara.
\end{abstract}

Kata Kunci: Metode Stepwise, koefisien determinasi, beras, Sulawesi Utara.

\section{DETERMINING THE BEST REGRESSION MODEL USING STEPWISE METHOD (CASE STUDY: RICE IMPORTS IN NORTH SULAWESI)}

\begin{abstract}
Indonesia has a large agricultural land and certainly able to supply for people, but in reality the rice production in Indonesia has not been able to complete the demands of the people, so the government took the policy to import rice. The purpose of this research is to determine the variables that affecting rice imports in North Sulawesi and determine the best regression model. The research was held in Manado City, North Sulawesi and lasted for five months from November 2016 to April 2017. The data used is secondary data of Statistics Indonesia and processed from book North Sulawesi in Figures 2008-2016. The data were analyzed by Stepwise Regression Method. The variables that influence rice import in North Sulawesi are the receipt of domestic rice (X4) and unpaid import devisa at excise Bitung customs and excise office (X8) which make the best regression model $\hat{Y}=26322,228-0,626 X_{4}+0.001 X_{8}$, with $\mathrm{R}$-sqr $=93,7 \%$ and $\mathrm{R}$-adj $=91,8 \%$. These variables are good to estimate the number of rice imports in North Sulawesi.
\end{abstract}

Keywords: Stepwise method, coefficient of determination, rice, North Sulawesi

\section{PENDAHULUAN}

Indonesia memiliki lahan pertanian yang cukup besar, tentulah harus dapat menghasilkan bahan pangan yang cukup untuk dikonsumsi penduduknya bahkan hasil produksi dapat melebihi kebutuhan masyarakat, pangan dalam hal ini yaitu beras. Kenyataan saat ini, produksi beras di Indonesia belum dapat memenuhi 
permintaan masyarakat sehingga mengharuskan pemerintah Indonesia untuk mengadakan impor beras agar dapat mencukupi kebutuhan dalam negeri (Badrudin, 2011).

Pengadaan impor berlaku bagi setiap provinsi di Indonesia termasuk Provinsi Sulawesi Utara. Disebut sebagai salah satu daerah penghasil beras di Indonesia tak lantas membuat Sulawesi Utara dapat mengandalkan hasil produksi daerah untuk pemenuhan kebutuhan. Agar kebutuhan beras masyarakat dapat tercukupi, pemerintah berupaya menambah pasokan beras dari luar daerah bahkan mengadakan permintaan ke luar negeri

Penelitian mengenai impor beras juga dilakukan dengan menggunakan 4 variabel bebas $(\mathrm{X})$ yaitu, produksi beras di Sulawesi Utara, konsumsi penduduk di Sulawesi Utara, Stok beras di Sulawesi Utara, dan Kurs dengan data masing-masing pada periode tahun 2002-2011 (Rungkat, 2014). Pada tahun 2013 juga dilakukan penelitian mengenai faktor-faktor yang mempengaruhi impor beras di Indonesia tahun 1980-2009 dengan hasil penelitian menunjukan variabel produksi beras dan variabel produksi domestik bruto jangka panjang berpengaruh signifikan terhadap impor beras di Indonesia (Kurniawan, 2013). Penelitian dengan metode yang sama dengan metode dalam penelitian ini yaitu regression stepwise forward juga pernah dilakukan dengan tujuan untuk menetukan persamaan linier berganda dalam kasus jumlah pendapatan di Tapanuli Utara yang mengahasilkan model regresi linier berganda dengan variabel bebas sektor pertanian $\left(\mathrm{X}_{1}\right)$ dan sektor bangunan $\left(\mathrm{X}_{5}\right)$ (Pakpahan, et al, 2013).

Berdasarkan uraian di atas maka tujuan dari penelitian ini yakni untuk medapatkan variabel-variabel yang membentuk model regresi terbaik dari impor beras di Sulawesi Utara.

\section{TINJAUAN PUSTAKA}

Pada model regresi, variabel dibedakan menjadi dua bagian yaitu variabel respon atau biasa juga disebut variabel bergantung serta variabel explanary atau biasa juga disebut variabel penduga atau disebut juga variabel bebas (Nawari, 2010).
Regresi linier terbagi atas dua jenis yaitu regresi linier sederhana dan regresi linier berganda. Regresi linier sederhana merupakan model regresi linier yang terdiri dari satu variabel tak bebas (Y) dan satu variabel bebas $(\mathrm{X})$ sedangkan regresi linier berganda merupakan model regresi yang terdiri dari satu variabel tak bebas dan memiliki lebih dari satu variabel bebas. Model regresi berganda adalah model yang mempelajari tentang ketergantungan peubah respon terhadap dua atau lebih peubah penjelas (Gujarati, 2006).

Peubah-peubah $X_{1, \ldots,} X_{p-1}$ di dalam suatu model regresi tidak harus mewakili peubah-peubah bebas yang berbeda, sebagaimana akan segera kita lihat. Oleh kerana itu kita dapat mendefinisikan model regresi linear umum, dengan suku-suku galat yang menyebar normal (Hatidja, 2006). Sebagai berikut:

$$
\begin{aligned}
Y_{i}= & \beta_{0}+\beta_{1} X_{1 i}+\beta_{2} X_{2 i}+\cdots+\beta_{p-1} X_{p-1, i} \\
& +\varepsilon_{i}
\end{aligned}
$$

Dalam hal ini :

$Y_{i}$ adalah variabel tidak bebas untuk pengamatan ke- $i$, untuk $i=1,2, \ldots, n$.

$\beta_{0}, \beta_{1}, \beta_{2}, \ldots, \beta_{p-1}$ adalah parameter

$X_{1 i}, X_{2 i}, \ldots, X_{p-1, i}$ adalah variabel bebas, untuk $i=1,2, \ldots, n$.

$\varepsilon_{i}$ adalah galat, yang saling bebas dan berdistribusi $N\left(0, \sigma^{2}\right)$.

Contoh beberapa penelitian yang berkaitan dengan analisis regresi yakni dilakukan penelitian tentang seberapa besar pengaruh variabel yang telah dipilih yaitu jumlah anggota keluarga (X1), luas lahan (X2), jumlah pohon pala (X3), jumlah produksi biji pala (X4), biaya tenaga kerja (X5) dan biaya produksi (X6) terhadap pendapatan petani pala di Desa Sensong dengan menggunakan analisis regresi berganda. Variabel yang memiliki pengaruh terhadap pendapatan petani pala adalah jumlah produksi biji pala (X4) dan biaya produksi (X6) (Lawendatu, et al, 2014). Contoh lainnya, pada tahun 2015 dilakukan penelitian tentang hubungan antara minat belajar dan hasil belajar matematika siswa SMA Kristen Eben Heazer Ibu dengan menggunakan analisis regresi. Dengan hasil secara statistika menyatakan tidak ada hubungan secara signifikan antara minat 
belajar dan hasil belajar matematika (Bunga, 2015).

\section{Uji Koefisien Determinasi}

Untuk mengetahui ketepatan atau kecocokan garis regresi yang terbentuk dalam mewakili kelompok data hasil observasi, perlu dilihat sampai seberapa jauh model yang terbentuk mampu menerangkan kondisi yang sebenarnya yang dikenal dengan nama koefisien determinasi $\left(\mathrm{R}^{2}\right)$. Nilai koefisien determinasi merupakan suatu ukuran yang menunjukan besar sumbangan dari variabel penjelasan terhadap respon (Siagaan dan Sugiarto, 2006).

$\mathrm{R}^{2}=1-\frac{\text { Jumlah Kuadrat Galat }(J K G)}{\text { Jumlah Kuadrat Total }(J K T)}$

Penambahan lebih banyak peubah bebas ke dalam model selalu akan menaikkan nilai $\mathrm{R}^{2}$ tidak pernah menurunkannya. Karena $\mathrm{R}^{2}$ sering bisa dibuat besar dengan cara menyertakan banyak peubah bebas, maka ada yang menyarankan agar ukuran ini dimodifikasi untuk mempertimbangkan banyaknya peubah bebas didalam model. Koefisien determinasi ganda terkoreksi (adjusted coefficient multiple determination), dilambangkan oleh $\mathbf{R}_{\text {adj }}$ mengoreksi $\mathbf{R}^{2}$ dengan cara membagi setiap jumlah kuadrat dalam rumus bagi $\mathrm{R}^{2}$ dengan derajat bebasnya masing-masing (Hatidja, 2006).

$$
\begin{aligned}
R_{a d j} & =1-\frac{J K G /(n-p)}{J K T /(n-1)} \\
& =1-\left(\frac{n-1}{n-p}\right)\left(\frac{J K G}{J K T}\right)
\end{aligned}
$$

\section{Uji Koefisien Regresi Secara Serentan (Uji F) Dan Parsial (Uji T)}

Untuk menguji apakah ada hubungan regresi antara peubah takbebas $\mathrm{Y}$ dengan peubah-peubah bebas $X_{1, \ldots,} X_{p-1}$, dengan kata lain untuk memilih di antara altenatifalternatif:

$H_{0}: \beta_{1}=\beta_{2}=\cdots=\beta_{p-1}=0$

Ha : tidak semua $\beta_{k}$ sama dengan nol

Kita menggunakan statistik uji :

$$
\mathrm{F}^{*}=\frac{K T R}{K T G}
$$

Kaidah keputusan dengan galat jenis 1 dikendalikan sebesar $\alpha$ adalah :

Jika $\mathrm{F}^{*} \leq \mathrm{F}(1-\alpha ; p-1, n-p)$, terima $\mathrm{H}_{0}$
Jika $\mathrm{F}^{*}>\mathrm{F}(1-\alpha ; p-1, n-p)$, terima $\mathrm{H}_{\mathrm{a}}$ (Hatidja, 2006).

Tujuan dari uji parsial adalah untuk mengetahui seberapa jauh pengaruh dari variabel independen $(\mathrm{X})$ terhadap variabel dependen (Y) secara parsial. Pengujian hipotesis akan dilakukan dengan menggunakan tingkat signifikan sebesar $0,05(\alpha=5 \%)$ atau tingkat keyakinan sebesar 0.95 (Ghozali, 2011). Hipotesis dirumuskan sebagai berikut :

$$
\begin{aligned}
& \mathrm{H}_{0}: \beta_{k}=0 \\
& \mathrm{H}_{\mathrm{a}}: \beta_{k} \neq 0
\end{aligned}
$$

Kita dapat menggunakan statistik uji :

$$
t^{*}=\frac{b_{k}}{s\left\{b_{k}\right\}}
$$

Kaidah keputusan :

Jika $\left|t^{*}\right| \leq t\left(\frac{\alpha}{2} ; n-p-1\right)$, terima $\mathrm{H}_{0}$

Jika selainnya, terima $\mathrm{H}_{\mathrm{a}}$ (Hatidja, 2006).

\section{Korelasi}

Koefisien korelasi adalah koefisien yang menggambarkan tingkat keeratan hubungan linier antara dua peubah bebas atau lebih. Besaran koefisien korelasi tidak menggambarkan hubungan sebab akibat antara dua peubah atau lebih tetapi sematamata menggambarkan keterkaitan linier antar peubah (Hatidja, 2006).

Koefisien korelasi antara peubah $\mathrm{X}$ dan $\mathrm{Y}$ dapat dirumuskan sebagai berikut:

$$
R_{x y}=\frac{n \sum X Y-\left(\sum X\right)\left(\sum Y\right)}{\sqrt{\left\{n \sum X^{2}-\left(\sum X\right)^{2}\right\}\left\{n \sum Y^{2}-\left(\sum Y\right)^{2}\right\}}}
$$

Keterangan :

$R_{x y}=$ koefisien korelasi variabel $\mathrm{X}$ dan $\mathrm{Y}$

$n=$ banyak pasangan variabel $\mathrm{X}$ dan $\mathrm{Y}$

Dalam analisis regresi dan korelasi berganda dikenal pula nilai koefisien korelasi parsial. Nilai koefisien korelasi parsial merupakan besaran nilai yang digunakan untuk mengukur tingkat keeratan hubungan antara dua variabel jika variabel lainnya konstan dalam suatu analisis yang melibatkan lebih dari dua variabel. Misalnya untuk korelasi antara variabel bebas pertama $\left(\mathrm{X}_{1}\right)$ dengan variabel terikat $(\mathrm{Y})$ apabila variabel bebas kedua $\left(\mathrm{X}_{2}\right)$ nilainya konstan. Adapun rumus untuk menentukan nilainya adalah:

$r_{Y 1.2}=\frac{r_{Y 1}-\left(r_{Y 2} \times r_{12}\right)}{\sqrt{\left.\left(1-r_{Y 2}^{2}\right) \times\left(1-r_{12}^{2}\right)\right)}}$ 
$r_{Y 1}=$ koefisien korelasi variabel $\mathrm{Y}$ dan $\mathrm{X}_{1}$

$r_{Y 2}=$ koefisien korelasi variabel $\mathrm{Y}$ dan $\mathrm{X}_{2}$

$r_{12}=$ koefisien korelasi variabel $\mathrm{X}_{1}$ dan $\mathrm{X}_{2}$

$r_{Y 1.2}=$ korelasi parsial antara Variabel $Y$ dan

$\mathrm{X}_{1}$ terhadap $\mathrm{X}_{2}$ (Sansota dan Purbayu, 2007).

\section{Uji Asumsi Klasik}

Sebelum dilakukan pengujian analisis regresi linier berganda terhadap hipotesis penelitian, maka terlebih dahulu perlu dilakukan suatu pengujian asumsi klasik atas data yang akan diolah.

Uji normalitas bertujuan untuk menguji apakah dalam model regresi, variabel pengganggu atau residual memiliki distribusi normal. Seperti diketahui bahwa uji $\mathrm{t}$ dan $\mathrm{F}$ mengasumsikan bahwa nilai residual mengikuti distribusi normal. Ada dua cara untuk mendeteksi apakah residual berdistribusi normal atau tidak yaitu dengan analisis grafik dan uji statistik. Untuk menguji apakah data berdistribusi normal atau tidak dilakukan uji statistik Kolmogorov-Smirnov Test. Residual berdistribusi normal jika memiliki nilai signifikansi >0,05 (Ghozali, 2011).

Uji heterokedastisitas bertujuan menguji apakah dalam model regresi terjadi ketidaksamaan variance dari residual satu pengamatan ke pengamatan yang lain. Ada beberapa cara yang dapat dilakukan untuk melakukan uji heteroskedastisitas, yaitu uji grafik plot, uji Park, uji Glejser, dan uji white. Untuk Grafik Plot dapat dilihat plot antara nilai prediksi variabel dependen yaitu standart predicted value (ZPRED) dengan standart residu (SRESID). Tidak terjadi heteroskedastisitas apabila tidak ada pola yang jelas, serta titik-titik menyebar di atas dan di bawah angka 0 pada sumbu $Y$ (Ghozali, 2011).

\section{Pemilihan Model Terbaik}

Prosedur langkah maju (The Forward Selection Procedure) ini merupakan suatu proses pencarian suatu model terbaik, yaitu dengan melakukan pengujian apakah suatu peubah yang telah dimasukkan perlu di keluarkan dari dalam model ataukah tidak (Jambormias, 2005).

Prosedur eliminasi langkah mundur (The Backward Elimination Procedure) ini merupakan kebalikan dari prosedur seleksi langkah maju. Prosedur ini dimulai dengan model yang mengandung semua peubah bebas potensial dan kemudian mengidentifikasikan peubah bebas dengan nilai $\mathrm{F}$ bagi regresi parsial yang paling kecil untuk dikeluarkan dari model (Jambormias, 2005).

Metode stepwise memilih peubah berdasarkan korelasi parsial terbesar dengan peubah yang sudah masuk dalam model. Peubah penjelas yang sudah masuk dalam model dapat saja dikeluarkan lagi (Hanum, 2011). Apabila salah satu peubah telah dimasukkan ke dalam model regresi, maka peubah lainnya tidak perlu dimasukkan lagi ke dalam model regresi karena pengaruhnya telah diwakili oleh peubah yang sudah masuk di dalam model regresi. Sehingga tidak terdapat multikolinieritas pada model regresi yang dihasilkan (Sembiring, 1995).

\section{METODOLOGI PENELITIAN}

Penelitian ini dilakukan pada bulan November 2016 sampai bulan April 2017 di Laboratorium Statistika Jurusan Matematika F-MIPA Universitas Sam Ratulangi.

\section{Data dan Variabel}

Data dalam penelitian ini menggunakan data sekunder yang diperoleh dari Badan Pusat Statistik dan Badan Pusat Statistik Provinsi Sulawesi Utara berupa data deret waktu (time series) dari tahun 2006-2015.

\section{Metode Analisis Data}

Analisis data penelitian menggunakan metode pemilihan model regresi terbaik yaitu regresi stepwise dengan penambahan prosedur seleksi langkah maju. Analisis data dilakukan dengan program IBM SPSS Statistics version 17. Adapun langkah analisisnya adalah sebagai berikut :

1. Mendefenisikan variabel terikat $\mathrm{Y}$ dan variabel bebas X.

2. Melakukan uji asumsi klasik

3. Mencari model terbaik dengan tahapan metode sebagai berikut :

i. Menentukan matriks korelasi antara variabel respon (Y) terhadap variabel bebas $(\mathrm{X})$.

ii. Pemilihan variabel yang pertama diregresikan yaitu variabel yang mempunyai harga mutlak koefisien 
korelasi terbesar terhadap respon (Y).

Tabel 1. Variabel-variabel yang Digunakan dalam Penelitian

\begin{tabular}{|c|c|c|c|}
\hline No. & $\begin{array}{l}\text { Nama } \\
\text { Variabel }\end{array}$ & Satuan & Penjelasan \\
\hline 1 & $\begin{array}{l}\text { Impor beras di } \\
\text { Sulawesi Utara } \\
(\mathrm{Y})\end{array}$ & Ton & $\begin{array}{l}\text { Penerimaan } \\
\text { beras dari luar } \\
\text { negeri }\end{array}$ \\
\hline 2 & $\begin{array}{l}\text { Produksi beras } \\
\text { Sulawesi Utara } \\
\left(\mathrm{X}_{1}\right)\end{array}$ & Ton & $\begin{array}{l}\text { Toal Hasil } \\
\text { panen beras }\end{array}$ \\
\hline 3 & $\begin{array}{l}\text { Stok beras di } \\
\text { Sulawesi Utara } \\
\left(\mathrm{X}_{2}\right)\end{array}$ & Ton & $\begin{array}{l}\text { Persedian beras } \\
\text { (stok akhir }+ \\
\text { penerimaan } \\
\text { beras) }\end{array}$ \\
\hline 4 & $\begin{array}{l}\text { Luas panen } \\
\text { padi Sulawesi } \\
\text { Utara }\left(\mathrm{X}_{3}\right)\end{array}$ & Ton & $\begin{array}{l}\text { Luas lahan } \\
\text { panen padi } \\
\text { sawah dan padi } \\
\text { ladang }\end{array}$ \\
\hline 5 & $\begin{array}{l}\text { Penerimaan } \\
\text { beras dari } \\
\text { dalam negeri di } \\
\text { Sulawesi Utara } \\
\left(\mathrm{X}_{4}\right)\end{array}$ & Hektar & $\begin{array}{l}\text { Penerimaan } \\
\text { beras dari } \\
\text { daerah-daerah di } \\
\text { Indonesia (move } \\
\text { regional dan } \\
\text { move in) }\end{array}$ \\
\hline 6 & $\begin{array}{l}\text { Devisa impor } \\
\text { paid pada bea } \\
\text { dan cukai } \\
\text { Bitung }\left(\mathrm{X}_{5}\right)\end{array}$ & Rupiah & $\begin{array}{l}\text { Penggunaan } \\
\text { devisa impor } \\
\text { yang sudah } \\
\text { dibayar }\end{array}$ \\
\hline 7 & $\begin{array}{l}\text { PDRB menurut } \\
\text { lapangan usaha } \\
\text { Sulawesi Utara } \\
\left(\mathrm{X}_{6}\right)\end{array}$ & $\begin{array}{l}\text { Jutaan } \\
\text { Rupiah }\end{array}$ & $\begin{array}{l}\text { nilai tambah } \\
\text { barang dan jasa } \\
\text { yang dihitung } \\
\text { menggunakan } \\
\text { harga yang } \\
\text { berlaku }\end{array}$ \\
\hline 8 & $\begin{array}{l}\text { Pendapatan } \\
\text { pajak daerah } \\
\text { Sulawesi Utara } \\
\left(\mathrm{X}_{7}\right) \\
\end{array}$ & $\begin{array}{l}\text { Jutaan } \\
\text { Rupiah }\end{array}$ & $\begin{array}{l}\text { Realisasi } \\
\text { pendapatan } \\
\text { pajak daerah. }\end{array}$ \\
\hline 9 & $\begin{array}{l}\text { Devisa impor } \\
\text { unpaid pada } \\
\text { bea dan cukai } \\
\text { Bitung }\left(\mathrm{X}_{8}\right)\end{array}$ & Rupiah & $\begin{array}{l}\text { Penggunaan } \\
\text { devisa yang } \\
\text { belum dibayar }\end{array}$ \\
\hline 10 & Kurs $\left(X_{9}\right)$ & Rupiah & $\begin{array}{l}\text { Nilai tukar } \\
\text { rupiah pada US } \\
\text { Dollar }\end{array}$ \\
\hline 11 & $\begin{array}{l}\text { Penduduk } \\
\text { Sulawesi Utara } \\
\left(\mathrm{X}_{10}\right)\end{array}$ & Jiwa & $\begin{array}{l}\text { Jumlah } \\
\text { penduduk }\end{array}$ \\
\hline
\end{tabular}

iii. Pembentukan regresi pertama yaitu regresi sederhana untuk variabel terpilih pada langkah ke-ii dan menguji keberartian regresi.

iv. Pemilihan variabel kedua diregresikan. Bila pada langkah ketiga ternyata terima $\mathrm{H}_{1}$ maka dilakukan pemilihan variabel kedua untuk diregresikan selanjutnya. Variabel terpilih adalah variabel sisa (di luar regresi) yang mempunyai parsial korelasi terbesar.

v. Pembentukan regresi kedua yaitu merupakan regresi ganda dan menguji keberartian regresi. Bila tidak signifikan maka proses dihentikan sedangkan sebaliknya bila signifikan maka lanjutkan seperti langka sebelumnya dengan memasukkan variabel sisa (di luar regresi) dengan harga mutlak koefisien korelasi terbesar terhadap respon $(\mathrm{Y})$.

vi. Pembentukan penduga apabila proses pemasukan variabel terhadap regresi sudah selesai, maka ditetapkan persamaan regresi yang menjadi penduga linier yang diinginkan yaitu merupakan persamaan regresi yang diperoleh terakhir.

4. Melakukan perbandingan model regresi yang diperoleh.

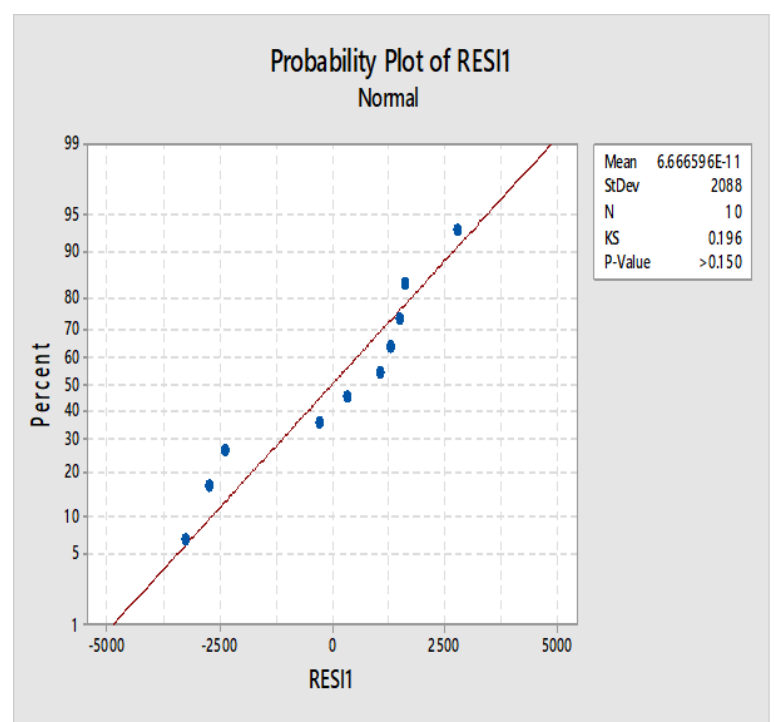

Gambar 1. Plot Normalitas

\section{HASIL DAN PEMBAHASAN Uji asumsi klasik \\ Normalitas}

Untuk hasil Uji Kolmogorov-Smirnof kita dapat mengambil keputusan berdasakan uji hipotesis sebagai berikut: 
$\mathrm{H}_{0}$ : Distribusi data memenuhi asumsi normalitas

$\mathrm{H}_{1}$ : Distribusi data tidak memenuhi asumsi normalitas

Berdasarkan hasil Gambar 1 nilai $\mathrm{p}=0.150$ $>0.05$, maka terima $\mathrm{H}_{0}$, atau tidak terjadi perbedaan yang signifikan dan data tersebut normal.

\section{Heteroskedastisitas}

Pengambilan keputusan berdasarkan penglihatan Scatterplot akan memberikan persepsi yang berbeda-beda, maka selanjutkan akan digunakan Uji Glejser untuk mengambil kesimpulan yang tepat. Berdasarkan pengolahan dengan menggunakan SPSS 17.

Hipotesis yang digunakan yaitu :

$\mathrm{H}_{0}$ : tidak adanya heteroskedastisitas

$\mathrm{H}_{1}$ : adanya heteroskedastisitas

$X_{1}, X_{2} X_{3}, X_{4} X_{5}, X_{8}, X_{9}, X_{10}$ memiliki nilai $\mathrm{p}$ masing-masing $>0.05$, maka terima $\mathrm{H}_{0}$ atau dapat disimpulkan bahwa tidak ada indikasi Heteroskedastisitas

\section{Stepwise}

\section{Uji keberartian persamaan regresi pertama}

Berdasarkan matriks korelasi variabel yang mempunyai nilai mutlak koefisien korelasi terbesar terhadap $Y$ adalah $X_{8}$. Maka selanjutnya yang diregresikan adalah $Y$ terhadap $X_{8}$. Karena nilai $\mathrm{p}<\alpha$ atau 0,005 $<0,05$ maka tolak $\mathrm{H}_{0}$, regresi antara $Y$ dan $X_{8}$ berarti. Maka variabel devisa impor unpaid pada bea dan cukai Bitung $\left(X_{8}\right)$ tetap dalam regresi.

\section{Uji Keberartian Persamaan Regresi Kedua}

Yang memiliki nilai mutlak korelasi parsial terbesar adalah $X_{4}\left[r_{(Y 4.8)}=0,905\right]$, sehingga $X_{4}$ terpilih sebagai variabel kedua untuk diregresikan. Karena nilai $\mathrm{p}<\alpha$ atau $0,000<0,05$ maka tolak $\mathrm{H}_{0}$, regresi antara $Y$, $X_{4}$ dan $X_{8}$ berarti. Variabel penerimaan beras dari dalam negeri di Sulawesi Utara $\left(X_{4}\right)$ tetap dalam regresi karena memiliki nilai signifikan dari $\quad X_{4}=0,001$ atau < 0.05 , maka secara parsial penerimaan beras dari dalam negeri di Sulawesi Utara $\left(X_{4}\right)$ berpengaruh secara signifikan terhadap impor beras di Sulawesi Utara $(Y)$.

\section{Uji Keberartian Persamaan Regresi Ketiga}

Nilai mutlak korelasi parsial terbesar adalah $X_{2}\left[r_{(Y 2.84)}\right]=0,693$, sehingga $X_{2}$ terpilih sebagai variabel ketiga untuk diregresikan. Karena nilai $\mathrm{p}<\alpha$ atau $0,000<$ 0,05 maka tolak $\mathrm{H}_{0}$, regresi antara $Y, X_{2}$, $X_{4}$ dan $X_{8}$ berarti. Untuk uji keberartian variabel stok beras di Sulawesi Utara $\left(X_{2}\right)$, nilai p $X_{2}=0,057$ atau $>0,050$ maka secara parsial stok beras di Sulawesi Utara $\left(X_{2}\right)$ tidak berpengaruh secara signifikan terhadap impor beras di Sulawesi Utara $(Y)$, atau koefisien regresi variable tersebut tidak berarti.

Berdasarkan keadaan ini, maka stok beras di Sulawesi Utara $\left(X_{2}\right)$ tidak masuk (keluar) dari model regresi. Berarti proses pemasukan variable ke dalam regresi telah selasai. Berdasarkan keadaan ini, maka stok beras di Sulawesi Utara $\left(X_{2}\right)$ tidak masuk (keluar) dari model regresi. Berarti proses pemasukan variable ke dalam regresi telah selasai dan regresi yang memenuhi adalah regresi dengan variabel penerimaan beras dari dalam negeri di Sulawesi Utara $\left(X_{4}\right)$ dan devisa impor unpaid pada bea dan cukai Bitung $\left(X_{8}\right)$.

Maka Persamaan penduga dari model regresi terbaik yang diperoleh adalah :

$$
\hat{Y}=26322,228+0,001 X_{8}-0,626 X_{4}
$$

Nilai $R^{2}=93,7 \%$ dan $\left(R_{\text {adj }}\right)=91,8 \%$.

\section{Stepwise Pada Kondisi Tertentu}

Dalam suatu kondisi tertentu, penulis ingin memasukkan variabel lain dalam menentukkan model terbaik, misalnya memasukkan variabel produksi beras di Sulawesi Utara $\left(X_{1}\right)$ ke dalam model terbaik yang akan dibentuk. Diasumsikan bahwa Produksi beras berpengaruh terhadap impor beras di Sulwesi Utara, dan variabel Produksi beras di Sulawesi Utara $\left(X_{1}\right)$ sudah masuk kedalam model terbaik maka selanjutnya melakukkan langkah Stepwise seperti biasa untuk mencari variabel-variabel lainnya yang akan masuk kedalam model.

\section{Uji Keberartian Persamaan Regresi Pertama}

Nilai mutlak korelasi parsial terbesar adalah $X_{8}\left[r_{(Y 8.1)}=0,826\right]$, sehingga $X_{8}$ terpilih sebagai variabel untuk diregresikan. Karena nilai $\mathrm{p}<\alpha$ atau $0,016<0,05$ maka 
tolak $\mathrm{H}_{0}$, regresi antara $Y, X_{1}$ dan $X_{8}$ berarti. Variabel devisa impor unpaid pada bea dan cukai Bitung $\left(X_{8}\right)$ tetap dalam regresi karena memiliki nilai signifikan dari $X_{8}=0,006$ atau $<0,05$, maka secara parsial devisa impor unpaid pada bea dan cukai Bitung $\left(X_{8}\right)$ berpengaruh secara signifikan terhadap impor beras di Sulawesi Utara $(Y)$.

\section{Uji Keberartian Persamaan Regresi Kedua}

Nilai korelasi mutlak parsial terbesar adalah $X_{4}\left[r_{\left(Y X_{4} X_{1} X_{8}\right)}=0,904\right]$, sehingga $X_{4}$ terpilih sebagai variabel kedua untuk diregresikan. Karena nilai $\mathrm{p}<\alpha$ atau $0,000<$ 0,05 maka tolak $\mathrm{H}_{0}$, regresi antara $Y$, $X_{1}, X_{4}$ dan $X_{8}$ berarti. variabel penerimaan beras dari dalam negeri di Sulawesi Utara $\left(X_{4}\right)$ tetap dalam regresi karena memiliki nilai signifikan dari $X_{4}=0,002$ atau < 0.05 , maka secara parsial penerimaan beras dari dalam negeri di Sulawesi Utara $\left(X_{4}\right)$ berpengaruh secara signifikan terhadap impor beras di Sulawesi Utara $(Y)$.

\section{Uji Keberartian Persamaan Regresi Ketiga}

Nilai parsial korelasi terbesar adalah $\left.X_{2}\left[r_{(Y 2.184)}=0,645\right)\right]$ sehingga $X_{2}$ terpilih sebagai variabel ketiga untuk diregresikan. Karena nilai $\mathrm{p}<\alpha$ atau $0,001<0,05$ maka tolak $\mathrm{H}_{0}$, regresi antara $Y, X_{1}, X_{2}, X_{4}$ dan $X_{8}$ berarti. Untuk uji keberartian variabel stok beras di Sulawesi Utara $\left(X_{2}\right)$, nilai $\mathrm{p}$ $X_{2}=0.118$ atau $>0,050$ maka secara parsial stok beras di Sulawesi Utara $\left(X_{2}\right)$ tidak berpengaruh secara signifikan terhadap impor beras di Sulawesi Utara $(Y)$, atau koefisien regresi variabel tersebut tidak berarti.

Berdasarkan keadaan ini, maka stok beras di Sulawesi Utara $\left(X_{2}\right)$ tidak masuk (keluar) dari model regresi. Berarti proses pemasukan variable ke dalam regresi telah selasai dan regresi yang memenuhi adalah regresi dengan variabel Produksi beras di Sulawesi Utara $\left(X_{1}\right)$, penerimaan beras dari dalam negeri di Sulawesi Utara $\left(X_{4}\right)$ dan devisa impor unpaid pada bea dan cukai Bitung $\left(X_{8}\right)$.

Maka Persamaan penduga dari model regresi terbaik yang diperoleh adalah :

$$
\begin{gathered}
\hat{Y}=41550,085-0,028 X_{1}+0,001 X_{8} \\
-0,602 X_{4}
\end{gathered}
$$

Nilai $R^{2}=94,4 \%$ dan $R_{a d j}=91,6 \%$.

\section{Stepwise Secara Langsung Dengan Menggunakan Software Spss 17}

Stepwise dapat dihitung secara langsung dengan menggunakan Software SPSS 17. Hasil yang didapatkan dalam Tabel 2.

Tabel 2. Hasil Analisis dengan Software

\begin{tabular}{|c|c|c|c|}
\hline Model & $\begin{array}{c}\text { Variables } \\
\text { Entered }\end{array}$ & $\begin{array}{l}\text { Variables } \\
\text { Removed }\end{array}$ & Method \\
\hline 1 & X8 & & $\begin{array}{l}\text { Stepwise (Criteria: Probability- } \\
\text { of-F-to-enter }<=.050 \text {, } \\
\text { Probability-of-F-to-remove >= } \\
.100) \text {. }\end{array}$ \\
\hline 2 & $x 4$ & & $\begin{array}{l}\text { Stepwise (Criteria: Probability- } \\
\text { of-F-to-enter }<=.050 \text {, } \\
\text { Probability-of-F-to-remove }>= \\
.100) \text {. }\end{array}$ \\
\hline
\end{tabular}
Variables Entered/Removed $^{\mathrm{a}}$

a. Dependent Variable: Y

Coefficients $^{a}$

\begin{tabular}{|l|r|r|r|r|r|}
\hline \multirow{2}{*}{ Model } & \multicolumn{2}{|c|}{$\begin{array}{c}\text { Unstandardized } \\
\text { Coefficients }\end{array}$} & $\begin{array}{c}\text { Standardized } \\
\text { Coefficients }\end{array}$ & & \\
\cline { 1 - 5 } & \multicolumn{1}{c|}{$\mathrm{B}$} & Std. Error & $\mathrm{b}$ & \multicolumn{1}{c|}{$\mathrm{t}$} & Sig. \\
\hline 1 (Constant) & -1168.368 & 6966.689 & & -.168 & .871 \\
X8 & .001 & .000 & .807 & 3.863 & .005 \\
\hline 2 (Constant) & 26322.228 & 5836.263 & & 4.510 & .003 \\
X8 & .001 & .000 & .723 & 7.506 & .000 \\
X4 & -.626 & .111 & -.541 & -5.614 & .001 \\
\hline
\end{tabular}

a. Dependent Variable: $Y$

Berdasakan hasil diatas yang merupakan output dari program, terlihat bahwa variabel yang masuk kedalam model adalah penerimaan beras dari dalam negeri di Sulawesi Utara $\left(X_{4}\right)$ dan devisa impor unpaid pada bea dan cukai Bitung $\left(X_{8}\right)$, sama seperti perhitungan pada langkahlangkah manual, maka persamaan model regresi terbaik adalah sebagai berikut :

$$
\hat{Y}=26322,228+0,001 X_{8}-0,626 X_{4}
$$

\section{Uji Serentak Untuk Seluruh Variabel Bebas}

Untuk melakukan perbandingan model, maka dilakukan juga uji serentak atau uji $\mathrm{F}$ untuk seluruh variabel bebas yang ada. Model regresi yang terbentuk adalah sebagai berikut :

$$
\begin{aligned}
\hat{Y}= & 866694,726+0,367 X_{1}-1,274 X_{2} \\
& -0,063 X_{3}-0,511 X_{4}+0,001 X_{8} \\
& +6,707 X_{8}-0,486 X_{10}
\end{aligned}
$$


Karena nilai $\mathrm{p}>\alpha$ atau $0,198>0,05$ maka terima $\mathrm{H}_{0}$, artinya bahwa variabelvariabel $X$ tidak memberi pengaruh signifikan terhadap impor beras di Sulawesi Utara (Y). Nilai $R^{2}=99,2 \%$ dan $R_{a d j}=$ $92,5 \%$.

\section{Perbandingan Model Regresi}

Tabel 3. Perbandingan Model Regresi berdasarkan nilai $\mathrm{R}^{2}$ dan $\mathrm{R}_{\mathrm{adj}}$

\begin{tabular}{|l|l|c|c|}
\hline No & $\begin{array}{l}\text { Variabel bebas } \\
\text { model regresi }\end{array}$ & $\mathbf{R}^{\mathbf{2}}$ & $\mathbf{R}_{\text {adj }}$ \\
\hline 1 & $\mathrm{X} 4, \mathrm{X} 8$ & $93,7 \%$ & $91,8 \%$ \\
\hline 2 & $\mathrm{X} 1, \mathrm{X} 4, \mathrm{X} 8$ & $94,4 \%$ & $91,6 \%$ \\
\hline 3 & $\begin{array}{l}\mathrm{X} 1, \mathrm{X} 2, \mathrm{X} 3, \mathrm{X} 4, \\
\mathrm{X} 5, \mathrm{X} 8, \mathrm{X} 9, \\
\mathrm{X} 10\end{array}$ & $99,2 \%$ & $92,5 \%$ \\
\hline
\end{tabular}

Indikator yang digunakan dalam proses penentuan model regresi terbaik adalah korelasi dan korelasi parsial masingmasing variabel dan untuk indikator penentuan model regresi terbaik adalah nilai $\mathrm{R}^{2}$ dan $\mathrm{R}_{\mathrm{adj}}$ dari masing-masing model yang ada.

Berdasakan nilai-nilai dari $\mathrm{R}^{2}$ dan $\mathrm{R}_{\mathrm{adj}}$, model regresi pertama yang merupakan hasil dari analisis metode stepwise cukup baik digunakan untuk menduga besar jumlah impor beras di Sulawesi Utara, dengan nilai $\mathrm{R}_{\mathrm{adj}}=91.8 \%$ yang artinya sebesar $91.8 \%$ keragaman dari impor beras di Sulawesi Utara (Y) bisa dijelaskan dengan model regresi pertama, dan sisanya dijelaskan oleh faktor lain. Model regresi pertama adalah sebagai berikut :

$$
\hat{Y}=26322,228+0,001 X_{8}-0,626 X_{4} \text {. }
$$

Pada saat devisa impor unpaid pada bea dan cukai Bitung $\left(X_{8}\right)$ dan penerimaan beras dari dalam negeri di Sulawesi Utara $\left(X_{4}\right)$ bernilai nol, maka besarnya dugaan nilai impor beras di Sulawesi Utara $(\hat{Y})$ adalah sebesar 26322,228. Apabila devisa impor unpaid pada bea dan cukai Bitung $\left(X_{8}\right)$ naik satu satuan maka impor beras $(\hat{Y})$ bertambah 0,001 dan apabila penerimaan beras dari dalam negeri di Sulawesi Utara $\left(X_{4}\right)$ naik satu satuan maka impor beras $(\hat{Y})$ berkurang sebesar 0,626.

\section{KESIMPULAN}

1. Variabel-variabel yang mempengaruh impor beras di Sulawesi Utara adalah penerimaan beras dari dalam negeri $\left(X_{4}\right)$ dan Devisa Impor Unpaid Pada Bea dan Cukai Bitung $\left(X_{8}\right)$, dan merupakan variabel yang membentuk model regresi terbaik dari Impor beras di Sulawesi Utara.

2. Model regresi terbaik dari impor beras di Sulawesi Utara adalah $\hat{Y}=26322,228+0.001 X_{8}-0,626 X_{4}$ Nilai $R^{2}=93,7 \%$ dan nilai $\left(R_{\text {adj }}\right)=91,8$ $\%$.

\section{DAFTAR PUSTAKA}

Badrudin, R. 2012. Ekonomika Otonomi Daerah. UPP STIM YKPN, Yogyakarta.

Bunga, K., J. Prang., dan N. Nainggolan. 2015. Hubungan antara Minat Belajar dan Hasil Belajar Matematika siswa SMA Kristen Eben Heazer Ibu dengan Menggunakan Analisis Regresi. Jurna de Cartesian 2(4): 224-228.

Ghozali, I. 2011. Aplikasi Analisis Multivariate Dengan Program IBM SPSS 19 (edisi kelima.) Semarang: Universitas Diponegoro.

Gujarati, D. 2006. Ekonometrika Dasar Diterjemahkan oleh Sumarto Zain. Erlangga. Jakarta.

Hanum, H. 2011. Perbandingan Metode Stepwise, Best Subset Regression, dan Fraksi dalam Pemilihan Model Regresi Berganda Terbaik. Jurnal Penelitian Sains. 14(2A): 1-6.

Hatidja, D. 2006. Analisis Regresi. Bahan Ajar. Manado : Materi Mata Kuliah Untuk Mahasiswa Semester IV Jurusan Matematika FMIPA UNSRAT

Jambormias，E. 2005. Prosedur Pemilihan Model Regresi Terbaik (Dengan Interpretasi Keluaran Program Minitab Dan Sas). Bahan ajar. Ambon.

Kurniawan, H. 2013. Faktor-faktor yang Mempengaruhi Impor Beras di Indonesia tahun 1980-2009 [Skripsi]. Fakultas Ekonomi, Semarang. 
Lawendatu, J., J. Kekenusa., dan D. Hatidja. 2014. Regresi Linier Berganda untuk Menganalisis Pendapatan Petani Pala. Jurnal de Cartesian 1(3):66-72.

Nawari, 2010. Analisis Regresi dengan MS Excel 2007 dan SPSS. PT Elex Media Komputindo. Jakarta.

Pakpahan, L., R. Sitepu., dan M. Situmorang. 2013. Penggunaan Metode Stepwise Forward untuk Menentukan Persamaan Regresi Linier Berganda. Jurnal Saintia Matematika 4(1): 383-397.

Rungkat, D. 2014. Analisis Faktor-Faktor Yang Mempengaruhi Impor Beras Di Sulawesi Utara. Jurnal Cocos 4(2):182-198.

Santosa, P., B. Purbayu. 2007. Statistika Deskriptif dalam Bidang Ekonomi dan Niaga. Erlangga. Jakarta.

Sembiring, R. K. 1995. Analisis Regresi. ITB. Bandung.

Siagaan, D., Sugiarto. 2006. Metode Statistika Untuk Bisnis dan Ekonomi. PT Gramedia Pustaka Utama. Jakarta. 